\title{
Functional heartburn has more in common with functional dyspepsia than with non-erosive reflux disease
}

\author{
E Savarino, ${ }^{1}$ D Pohl, ${ }^{2}$ P Zentilin, ${ }^{1}$ P Dulbecco, ${ }^{1}$ G Sammito, ${ }^{1}$ L Sconfienza, ${ }^{1}$ S Vigneri, ${ }^{3}$ \\ G Camerini, ${ }^{4}$ R Tutuian, ${ }^{2}$ V Savarino ${ }^{1}$
}

${ }^{1}$ Division of Gastroenterology, Department of Internal

Medicine, University of Genoa, Genoa, Italy; ${ }^{2}$ Division of

Gastroenterology and Hepatology, Department of Internal Medicine, University Hospital Zurich, Zurich, Switzerland; ${ }^{3}$ Division of Gastroenterology, Department of Internal Medicine, University of Palermo, Palermo, Italy;

${ }^{4}$ Division of Surgery,

Department of Internal Medicine, University of Genoa, Genoa, Italy

Correspondence to: Dr E Savarino, Cattedra di Gastroenterologia, Università $\mathrm{d}$ Genova, Viale Benedetto XV, 16100 Genova, Italy; edoardo.savarino@unige.it

Revised 6 April 2009 Accepted 16 April 2009 Published Online First 20 May 2009

\section{ABSTRACT}

Introduction: Functional dyspepsia and non-erosive reflux disease (NERD) are prevalent gastrointestinal conditions with accumulating evidence regarding an overlap between the two. Still, patients with NERD represent a very heterogeneous group and limited data on dyspeptic symptoms in various subgroups of NERD are available.

Aim: To evaluate the prevalence of dyspeptic symptoms in patients with NERD subclassified by using $24 \mathrm{~h}$ impedance-pH monitoring (MII-pH).

Methods: Patients with typical reflux symptoms and normal endoscopy underwent impedance-pH monitoring off proton pump inhibitor treatment. Oesophageal acid exposure time (AET), type of acid and non-acid reflux episodes, and symptom association probability (SAP) were calculated. A validated dyspepsia questionnaire was used to quantify dyspeptic symptoms prior to reflux monitoring.

Results: Of 200 patients with NERD (105 female; median age, 48 years), 81 (41\%) had an abnormal oesophageal AET (NERD pH-POS), 65 (32\%) had normal oesophageal AET and positive SAP for acid and/or non-acid reflux (hypersensitive oesophagus), and 54 (27\%) had normal oesophageal AET and negative SAP (functional heartburn). Patients with functional heartburn had more frequent $(p<0.01)$ postprandial fullness, bloating, early satiety and nausea compared to patients with NERD pH-POS and hypersensitive oesophagus.

Conclusion: The increased prevalence of dyspeptic symptoms in patients with functional heartburn reinforces the concept that functional gastrointestinal disorders extend beyond the boundaries suggested by the anatomical location of symptoms. This should be regarded as a further argument to test patients with symptoms of gastro-oesophageal reflux disease in order to separate patients with functional heartburn from patients with NERD in whom symptoms are associated with gastrooesophageal reflux.

Gastro-oesophageal reflux disease (GORD) is one of the most common chronic gastrointestinal diseases in Western countries. ${ }^{12}$ Recent studies documented that up to $70 \%$ of reflux patients have typical reflux symptoms (ie, heartburn and/or regurgitation) in the absence of endoscopically visible oesophageal mucosal injuries, making nonerosive reflux disease (NERD) the more common form of GORD. ${ }^{3}$ The NERD patient group incorporates subgroups which differ significantly in terms of presentation, pathophysiology and management. Patients experiencing typical reflux symptoms without evidence of oesophagitis on upper endoscopy are classified on the basis of oesophageal $\mathrm{pH}$ monitoring results and symptom association analysis as suffering either from NERD, when excessive acid reflux or a positive symptom association with acid reflux is demonstrated, or from functional heartburn (FH), when, in agreement with Rome III criteria, distal oesophageal acid exposure is normal and a negative response to acid suppression is found. ${ }^{56}$ Recognising that stimuli other than acid can evoke typical reflux symptoms, ${ }^{7}$ our group previously proposed subclassifying patients with typical reflux symptoms and normal upper gastrointestinal endoscopy as follows: (1) NERD pH-POS patients with normal endoscopy and abnormal distal oesophageal acid exposure; (2) hypersensitive oesophagus - patients with normal endoscopy, normal distal oesophageal acid exposure and positive symptom association for either acid or non-acid reflux; and (3) functional heartburn - patients with normal endoscopy, normal distal oesophageal acid exposure and negative symptom association for acid and nonacid reflux.

Patients with GORD, both with erosive oesophagitis and NERD, frequently report dyspeptic symptoms. ${ }^{9}$ Epidemiological studies investigating the prevalence of dyspeptic and oesophageal symptoms have reported a higher prevalence of dyspeptic symptoms in patients with GORD, suggesting that the degree of overlap is greater than could be predicted by chance alone. ${ }^{10}$ Moreover, it was recently demonstrated that patients with functional heartburn and poor response to acid suppressive therapy are more likely to have psychopathology similarly to patients with functional dyspepsia. ${ }^{11}$ Last, but not least, abdominal symptoms appear to be independent predictors of the severity of reflux symptoms in patients with NERD when compared to normal controls. ${ }^{12}$

Given previous reports indicating an inverse relationship between dyspeptic symptoms and the objective criteria for GORD we hypothesised that in patients with functional heartburn dyspeptic symptoms should be more prevalent compared to the rest of NERD patients. To test this hypothesis, we evaluated the prevalence of dyspeptic symptoms in patients with NERD subclassified into three distinct groups by using $24 \mathrm{~h}$ MII$\mathrm{pH}$ monitoring.

\section{METHODS}

\section{Study subjects}

Between June 2004 and September 2008, patients presenting to the outpatient motility centre at the 
University of Genoa with predominant typical GORD symptoms (ie, heartburn and regurgitation) lasting for more than 6 months and occurring at least three times weekly, were prospectively enrolled in the study. All subjects who agreed to participate in our investigation underwent careful history taking physical and clinical examination, upper gastrointestinal endoscopy to assess the presence or not of oesophageal mucosal injury, routine biochemistry, and upper abdominal ultrasound. The medical history included information on treatment with acid suppressive medication (in particular proton pump inhibitors (PPIs)) and symptomatic response to PPI therapy. Patients reporting $\geqslant 50 \%$ symptom improvement were considered responders to PPI therapy. Patients treated with antisecretory drugs were asked to discontinue acid suppressive therapy at least 30 days before the endoscopic examination. During the washout period, patients were allowed to use an oral antacid or alginate on an as-needed basis for the relief of heartburn. Based on the results of upper endoscopy, patients were then subdivided into three major groups - Barrett's oesophagus, erosive oesophagitis and NERD - in cases where the typical symptoms of GORD were present, and where visible oesophageal mucosal injury was absent. Patients with Barrett's oesophagus and erosive oesophagitis were not included in the present study. Within 1-5 days (median 3 days) from the upper endoscopy, patients with NERD underwent ambulatory combined impedance-pH monitoring. Exclusion criteria were: history of thoracic, oesophageal or gastric surgery; primary or secondary severe oesophageal motility disorders (eg, achalasia, scleroderma, diabetes mellitus, autonomic or peripheral neuropathy, myopathy); underlying psychiatric illness; use of nonsteroidal anti-inflammatory drugs (NSAIDs) and aspirin; presence of peptic stricture and duodenal or gastric ulcer on upper endoscopy, evidence of erosive oesophagitis at previous (2-5 years) endoscopy, presence of dyspeptic symptoms as major symptoms. In women of childbearing age, pregnancy was excluded by urine analysis. During upper gastrointestinal endoscopy, biopsies were taken from the antrum and the corpus for assessing the presence of Helicobacter pylori. Patients were asked to discontinue any medication that would influence oesophageal motor function at least 1 week before administering the questionnaires and performing tests of oesophageal function.

All participants gave written informed consent before entering the study.

\section{Symptom questionnaire}

Before the $24 \mathrm{~h} \mathrm{pH}$-impedance study, each patient completed a functional dyspepsia questionnaire as reported and validated previously. ${ }^{13}$ This questionnaire included questions on the presence and intensity (range, $0-3$; where $0=$ absent, $1=$ mild, $2=$ moderate, and $3=$ severe, interfering with daily activities) of epigastric pain, bloating, postprandial fullness, early satiety, nausea, vomiting, excessive belching and epigastric burning. Also, typical GORD symptoms (ie, heartburn and regurgitation) were evaluated using the same questionnaire $(0=$ absent, $1=$ mild, $2=$ moderate, and $3=$ severe). A second investigator completed a structured interview with the patient including a careful medical history (including height and weight), current medication, tobacco use and alcohol consumption.

\section{Oesophageal multichannel intraluminal impedance and $\mathrm{pH}$ monitoring}

Oesophageal impedance-pH monitoring was performed using an ambulatory multichannel intraluminal impedance and $\mathrm{pH}$
(MII-pH) monitoring system (Sleuth; Sandhill Scientific, Highland Ranch, Colorado, USA). The system included a portable data logger and a catheter with one antimony $\mathrm{pH}$ electrode and eight impedance electrodes at 2, 4, 6, 8, 10, 14, 16 and $18 \mathrm{~cm}$ from the tip of the catheter. Each pair of adjacent electrodes represented an impedance-measuring segment $(2 \mathrm{~cm}$ length) corresponding to one recording channel. The six impedance and one $\mathrm{pH}$ signals were recorded at $50 \mathrm{~Hz}$ on a 128 MB CompactFlash (SanDisk, Milpitas, California, USA).

The methodology of probe calibration, catheter placement, patient instruction and performance have been previously described. ${ }^{8}$ On the monitoring day, each subject ate three standard meals of a Mediterranean diet as previously reported. ${ }^{14}$

The data stored on the CompactFlash card were downloaded into a personal computer and analysed using a semiautomated reflux detection algorithm (Autoscan; Sandhill Scientific). Tracings were subsequently reviewed manually by an expert reader (ES) in order to ensure accurate detection and classification of reflux episodes. Meal periods were excluded from the analysis.

\section{Definitions of reflux episodes}

Simultaneously recorded $\mathrm{pH}$ data were used to classify reflux episodes as acid, weakly acidic, or weakly alkaline according to the previously reported criteria: ${ }^{15}$

- Acid reflux: impedance-detected reflux episodes with a nadir $\mathrm{pH}$ less than 4

- Weakly acidic reflux: impedance-detected reflux episodes with a nadir $\mathrm{pH}$ between 4 and 7

- Weakly alkaline reflux: impedance-detected reflux episodes with a nadir $\mathrm{pH}$ above 7 . For symptom analysis, weakly acidic and weakly alkaline reflux were grouped together as non-acid reflux episodes (nadir $\mathrm{pH}>4$ )

\section{Gastro-oesophageal reflux parameters}

Impedance and $\mathrm{pH}$ data were used to determine the number and type of reflux episodes and distal oesophageal acid exposure (reflux time (min) and reflux per cent time) in each patient.

Total $24 \mathrm{~h}$ oesophageal acid exposure (\%) was defined as the total time when the $\mathrm{pH}$ was below 4 divided by the time of monitoring. A total distal oesophageal acid exposure (ie, per cent time at $\mathrm{pH}<4$ ) of less than $4.2 \%$ over $24 \mathrm{~h}$ was considered normal. $^{8} 14$

\section{Symptom-reflux association analysis}

In each patient we calculated the symptom association probability (SAP) for typical oesophageal symptoms. In the analysis we separated symptoms associated with acid reflux from those associated with non-acid reflux (including weakly acidic and weakly alkaline reflux as a whole) and symptoms occurring independent of reflux episodes. Separate analysis was performed for each individual symptom if patients recorded different types of symptoms.

The SAP was calculated for acid and non-acid reflux using a custom made Excel macro function (RT). The algorithm counted the number of symptoms preceded by a reflux episode within 2 min $(S+R+)$. The number of symptoms not associated with reflux $(S+R-)$ was calculated by subtracting $S+R+$ from the total number of symptoms. The study was divided into 2min segments in order to determine the number reflux containing segments $(R+)$ and reflux-free symptoms $(R-)$. The two other cells of the $2 \times 2$ contingency table $(S-R-$ and $\mathrm{S}-\mathrm{R}+$ ) were calculated by performing the corresponding 
Figure 1 Subclassification of patients with non-erosive reflux disease (NERD), based on distal oesophageal acid exposure and symptom association in NERD pH-POS (abnormal per cent time the $\mathrm{pH}$ was $<4$ ), hypersensitive oesophagus (normal per cent time $\mathrm{pH}<4$ and positive symptom association probability (SAP), and functional heartburn (normal per cent time the $\mathrm{pH}$ was $<4$, and negative SAP).

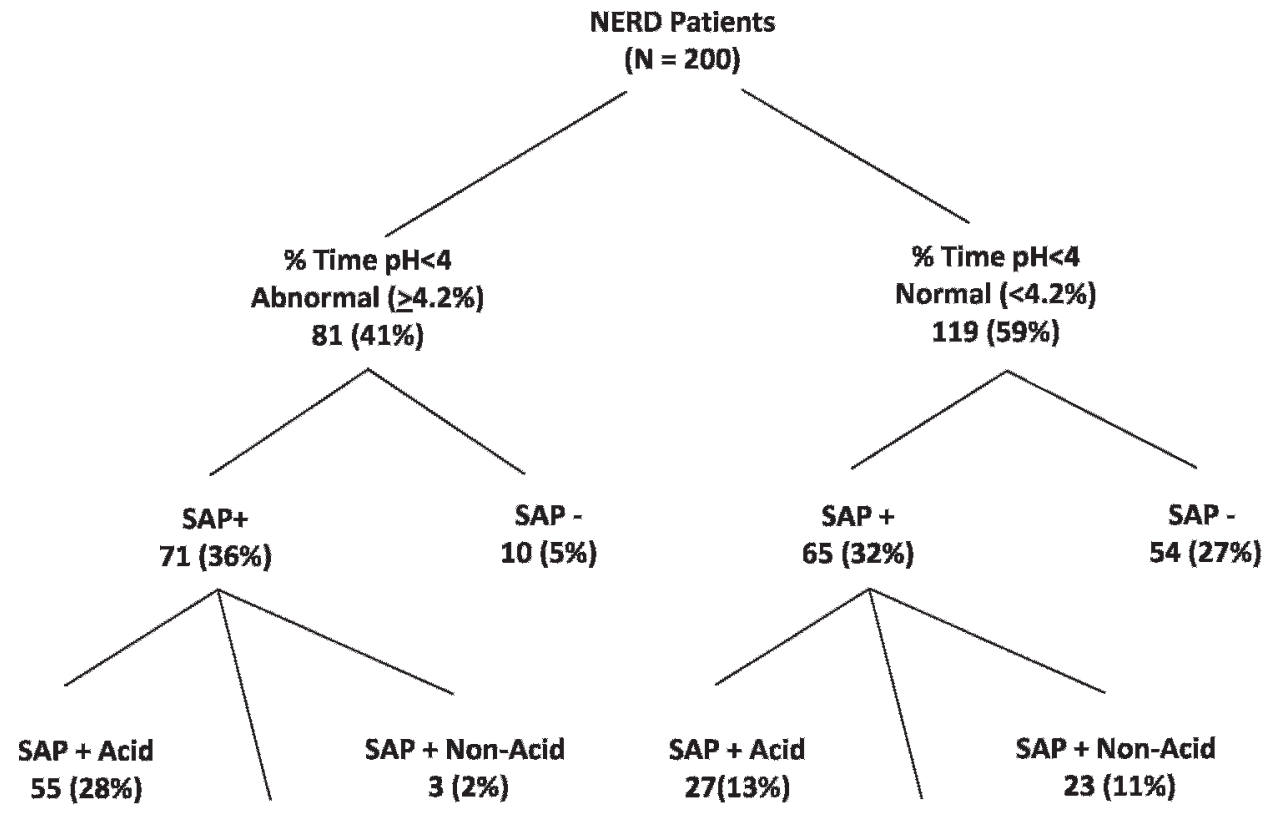

SAP + Acid and Non-Acid $13(6 \%)$ subtractions. A two-sided Fisher exact test was used to calculate the probability $(p)$ that the observed distribution could have been occurred by chance. SAP was calculated as $(1-p) \times 100 \%$ and was considered to be positive when $\geqslant 95 \%$ was positive. ${ }^{8}$

\section{Statistical analysis}

Continuous variables were compared using ANOVA (with post hoc comparisons between groups) or the Kruskal-Wallis test depending on the normal or abnormal distribution of data (assessed by the Kolmogorov-Smirnov test). The $\chi^{2}$ test was used when comparing categorical variables (ie, the presence/ absence of Helicobacter pylori infection and individual dyspeptic symptoms). Differences were considered statistically significant when $\mathrm{p}<0.05$.

\section{RESULTS}

Two hundred and sixty-six patients with typical symptoms of GORD met the enrolment criteria and entered the study. Based on the results of upper endoscopy, eight patients had Barrett's oesophagus, 44 had erosive oesophagitis, and 214 had NERD. Patients with Barrett's oesophagus and erosive oesophagitis were not included in the present study. Of the patients with NERD, 200 (105 females, mean age 48 years, range 18-78) reported at least one type of typical gastro-oesophageal reflux symptom during the monitoring period and were included in the final analysis. Thirty-four patients $(17 \%)$ never received PPIs ("PPI naive" NERD patients). Combined impedance-pH monitoring was well tolerated by all subjects and no important technical failure occurred. The median total recording time was $23.4 \mathrm{~h}$ (range 22.9-23.6 h)

\section{Acid exposure and symptom association}

Acid exposure time and symptom association probability is shown in fig 1. Patients with NERD were subdivided into four different subgroups according to oesophageal acid exposure and symptom association. We found an abnormal distal oesophageal acid exposure time in $81(41 \%)$ patients, $71(36 \%)$ of whom had a positive SAP (NERD pH-POS/SAP+) and $10(5 \%)$ had no

Table 1 Demographic and clinical characteristics, treatment with proton pump inhibitors (PPIs), and treatment response of patients with non-erosive reflux disease $(n=200)$

\begin{tabular}{|c|c|c|c|c|c|}
\hline Demographic or clinical parameter & pH-POS/SAP+ & pH-POS/SAP- & pH-NEG/SAP+ & pH-NEG/SAP- & p Value \\
\hline Patients, no & 71 & 10 & 65 & 54 & \\
\hline Female patients, no & 29 & 4 & 35 & 37 & $<0.01$ \\
\hline Patients with clinically relevant dyspeptic symptoms, no & 26 & 4 & 24 & 34 & $<0.01$ \\
\hline Mean age, years (range) & $50.7(20-78)$ & $51.9(34-76)$ & $46.1(22-77)$ & $45.8(18-76)$ & NS \\
\hline Mean body mass index (range) & $26.7(18-42)$ & $27.3(20-38)$ & $23.5(19-41)$ & $22.9(16-34)$ & $<0.01$ \\
\hline Tobacco use, \% & 21.1 & 30.0 & 23.1 & 25.9 & NS \\
\hline Alcohol consumption, $\%$ & 40.8 & 40.0 & 33.8 & 35.2 & NS \\
\hline Coffee consumption, $\%$ & 80.3 & 80.0 & 73.8 & 77.8 & NS \\
\hline Prevalence of hiatal hernia, $\%$ & 76.1 & 80.0 & 43.1 & 42.6 & $<0.01$ \\
\hline Prevalence of Helicobacter pylori infection, \% & 8.5 & 10.0 & 9.2 & 9.3 & NS \\
\hline Patients having previously received PPIs, no (\%) & $46(65)$ & $6(60)$ & $62(95)$ & $52(96)$ & $<0.01$ \\
\hline Positive $(\geqslant 50 \%)$ symptom response, no (\%) & $34(74)$ & $4(67)$ & $33(53)$ & $15(29)$ & $<0.01$ \\
\hline
\end{tabular}

NEG, negative; POS, positive; SAP, symptom association probability. 

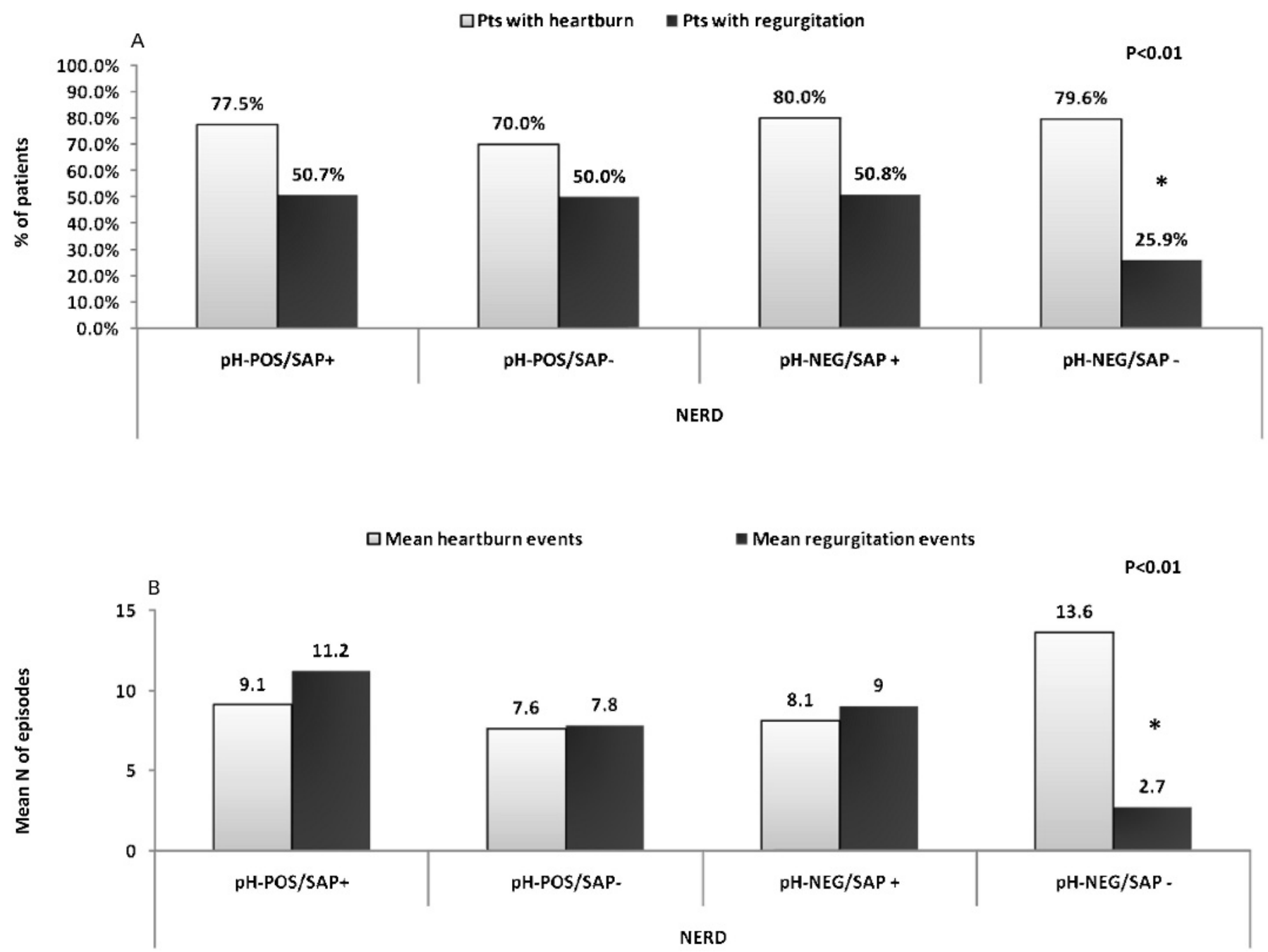

Figure 2 (A) Percentages of patients reporting typical symptoms of gastro-oesphageal reflux disease (GORD) stratified according to the results $(n=200)$ of $24 \mathrm{~h}$ impedance-pH monitoring. (B) Mean numbers of GORD symptoms stratified according to the results $(n=200)$ of $24 \mathrm{~h}$ impedance-pH monitoring. NEG, negative; POS, positive; Pts, patients; SAP, symptom association probability.

association between symptoms and any type of reflux (NERD $\mathrm{pH}-\mathrm{POS} / \mathrm{SAP}-$ ). One hundred and nineteen patients (59\%) had a normal distal oesophageal acid exposure (per cent time $\mathrm{pH}<4$ less than $4.2 \%$ ), 65 (32\%) of whom had a positive SAP (NERD pH-NEG/SAP+; hypersensitive oesophagus subgroup). Fiftyfour $(27 \%)$ patients had no association between symptoms and any type of reflux (NERD pH-NEG/SAP-; functional heartburn subgroup).

\section{Demographic and clinical characteristics}

Detailed demographic and clinical characteristics of the various subgroups of patients with NERD are shown in table 1 . There were no differences with respect to age, smoking, alcohol, coffee consumption and prevalence of $H$ pylori infection $(p=N S)$. The prevalence of hiatal hernia was higher in NERD pH-POS patients with positive SAP and negative SAP compared to those with hypersensitive oesophagus or $\mathrm{FH}$ (76.1 vs 80 vs 43.1 vs 42.6; $\mathrm{p}<0.01)$. Moreover, patients in the NERD $\mathrm{pH}-\mathrm{POS}$ subgroups had a higher mean body mass index than patients with hypersensitive oesophagus or FH (26.7 vs 27.3 vs 23.5 vs 22.9; $\mathrm{p}<0.01)$. Finally, patients of the functional heartburn subgroup were more frequently women than those in the other two subgroups (40 vs 40.8 vs $53.8 \%$ vs 68.5 ; $p<0.01$ ).

\section{Typical GORD symptoms in different subgroups of patients with NERD}

Patients with NERD had a median heartburn score of 2 (range 1-3) and a median regurgitation score of 2 (range $0-3$ ) recorded in the GORD symptoms questionnaires. Details on the number and percentages of patients on PPIs and the numbers and percentages of patients who responded to PPIs are shown in table 1.

Symptoms reported during the study day were in agreement with the symptom questionnaires. Indeed, 66 (93\%) patients with NERD pH-POS/SAP+ (median heartburn score 2), eight (80\%) with NERD pH-POS/SAP - (median heartburn score 2), 58 (89\%) NERD pH-NEG/SAP+ (median heartburn score 2) and 50 (93\%) NERD pH-NEG/SAP - (median heartburn score 2) reported heartburn, while 43 (61\%) patients with NERD pH-POS/SAP+ (median regurgitation score 2 ), five (50\%) with NERD pH-POS/ SAP - (median regurgitation score 2), 36 (55\%) NERD pH-NEG/ $\mathrm{SAP}+$ (median regurgitation score 2) and 18 (33\%) NERD pHNEG/SAP - (median regurgitation score 1 ) reported regurgitation.

The total number of symptoms reported by patients with NERD was 2245 (mean 4.5, range 1-69). Patients reported 1465 heartburn events (mean 10, range 1-62) and 780 regurgitation episodes (mean 9, range 1-69). Data on the number of heartburn and regurgitation events reported by patients in various subgroups of NERD are summarised in fig $2 \mathrm{~A}, \mathrm{~B}$. 


\section{Dyspepsia symptoms in different subgroups of patients with NERD}

As summarised in fig 3A, in the FH subgroup symptoms such as nausea, postprandial fullness, early satiety and bloating were more frequent compared to NERD pH-POS patients with both positive and negative SAP and those with hypersensitive oesophagus $(p<0.01)$. Epigastric pain and epigastric burning tended to be more frequent in patients of NERD $\mathrm{pH}-\mathrm{POS}$ with positive SAP and negative SAP subgroups, but statistical significance was not reached $(p=N S)$. Similar results were obtained when considering only moderate/severe dyspeptic symptoms (severity score $\geqslant 2$ ), as shown in fig $3 \mathrm{~B}$.

\section{DISCUSSION}

Upper gastrointestinal symptoms are remarkably common in the general population, with the majority of patients having GORD or dyspepsia. ${ }^{10}{ }^{16}$ Periodically updated international criteria, applying standardised questionnaires for symptom collection, have led to the classification of patients into distinct disease categories (currently, Rome III). Patients suffering from symptomatic heartburn and/or regurgitation are clinically classified as GORD - in the absence of oesophageal mucosa abnormalities as NERD - and not dyspepsia. In functional gastrointestinal disorders, however, a certain degree of overlapping symptoms has been reported, ${ }^{17-20}$ and this degree of overlap appears to be greater than would be predicted by chance alone.

Non-erosive or negative-endoscopy reflux disease (NERD) may account for up to $70 \%$ of patients with GORD in the community. ${ }^{8-10}$ NERD is a heterogeneous disorder and incorporates subgroups which differ significantly in terms of presentation, pathophysiology and management. Because of this heterogeneity, previous studies tried to differentiate NERD patients on the basis of acid exposure on $24 \mathrm{~h} \mathrm{pH}$ studies. However, this differentiation left some difficulties in distinguishing patients with true reflux disease from those with functional disease, reducing the possibility to evaluate the degree of overlap between NERD and functional dyspepsia or functional disorders as a whole. Recently, recognising that stimuli other than acid can evoke typical reflux symptoms, ${ }^{7}$ we have proposed subclassifying patients with NERD by using the combination of conventional $\mathrm{pH}$ with oesophageal intraluminal electrical impedance monitoring, in order to distinguish these patients more clearly on the basis of their distal oesophageal acid exposure or positive and/or negative symptom association to acid or non-acid reflux during the MII-pH recording. Applying this technique to the NERD population in current study, we reduced the proportion of patients who would have been previously labelled as presenting with $\mathrm{FH}$ as follows: (1) $41 \%$ as NERD pH-POS patients; (2) $32 \%$ as hypersensitive oesophagus patients; and (3) $27 \%$ as functional heartburn patients. These percentages are in agreement with those of a previous study in which we assessed 150 patients with NERD recruited in three Italian centres. ${ }^{8}$

In our study, prospectively collected $24 \mathrm{~h}$ ambulatory impedance-pH monitoring data and functional dyspepsia questionnaires in a large group of unselected NERD patients off PPI treatment led us to show that clinically relevant dyspeptic symptoms are present in $44 \%$ of the NERD population, in accordance with other investigations. ${ }^{18}$ Moreover, to our knowledge, this is the first study assessing in a large group of patients with NERD, off medication, the distribution of typical GORD and dyspepsia symptoms to evaluate the degree of overlap between functional dyspepsia and the different subgroups of the NERD population identified by means of MII-pH monitoring. In particular, we showed that subclassifying NERD patients into three different groups on the basis of $24 \mathrm{~h} \mathrm{pH}$-impedance results, dyspeptic symptoms are more frequently reported in patients with $\mathrm{FH}(63 \%)$ compared to the NERD pH-POS/SAP+ (37\%), NERD pH-POS/SAP$(36.6 \%)$ and hypersensitive oesophagus (37\%) subgroups, suggesting a significantly different degree of overlap of NERD subgroups with functional dyspepsia.

Patients now diagnosed with FH from the NERD collective reported much more frequently dyspeptic symptoms such as postprandial fullness, bloating, early satiety and nausea compared to the NERD $\mathrm{pH}-\mathrm{POS}$ with positive SAP and negative SAP and hypersensitive oesophagus subgroups. In particular, postprandial fullness and early satiation were the main symptoms more frequently related to the $\mathrm{FH}$ subgroup, suggesting a possible association between this disorder and the post prandial distress syndrome, as defined by Rome III criteria. ${ }^{17}{ }^{21}$ The same proportions in symptom prevalence were maintained when considering moderate/severe dyspeptic symptoms, and this further corroborates the fact that dyspeptic symptoms have a different prevalence among the various subgroups of NERD patients we identified by means of MII$\mathrm{pH}$. Moreover, we found that symptoms such as epigastric pain and epigastric burning were more frequently encountered in NERD $\mathrm{pH}$-POS with positive SAP and negative SAP patients, thus confirming previous controlled studies showing that epigastric pain syndrome is more prevalent in patients with abnormal $\mathrm{pH}$ test. $^{22}$ This is in keeping with findings from controlled studies showing that NERD patients with a positive $\mathrm{pH}$-metry are more likely to respond to proton pump inhibitor treatment, similarly to dyspeptic patients with predominant pain. ${ }^{23}$ Finally, the presence of a different distribution of dyspepsia symptoms in our patients confirms the existence of two different clinical dyspepsia patterns as assessed in the last Rome III consensus and here for the first time validated in a large group of NERD patients.

Moreover, if we look at the prevalence of typical reflux symptoms in our population, we found that NERD pH-POS with positive SAP and negative SAP patients more often experienced regurgitation episodes than did patients with $\mathrm{FH}$, with an increasing frequency during the recording period, suggesting that they have a GORD symptom pattern more similar to that of patients with erosive oesophagitis and Barrett's oesophagus than with $\mathrm{FH}^{1-4}$ The percentages of patients reporting heartburn were similar in our subgroups, but patients with $\mathrm{FH}$ reported more frequently heartburn during the monitoring. This certainly could have been influenced by psychosocial factors as suggested by Watson et al. ${ }^{11}$ Unfortunately, in the current study, psychological profiles were not collected in all patients. While available data (results not shown) indicating more frequently anxiety and/or depression in the $\mathrm{FH}$ patient group are consistent with recently published data on functional dyspepsia by van Odenhove et al, ${ }^{24}$ we are deferring further conclusions to an adequately designed and powered study evaluating the contribution of psychology features in symptom generation in patients with functional oesophageal disorders.

Finally, some demographic features were different in our subgroups. We found that NERD $\mathrm{pH}-\mathrm{POS}$ patients independently of the symptom association were more frequently male, had a higher mean body mass index and an increased prevalence of hiatal hernia, in agreement with those studies considering these demographic and clinical parameters as risk factors for the 

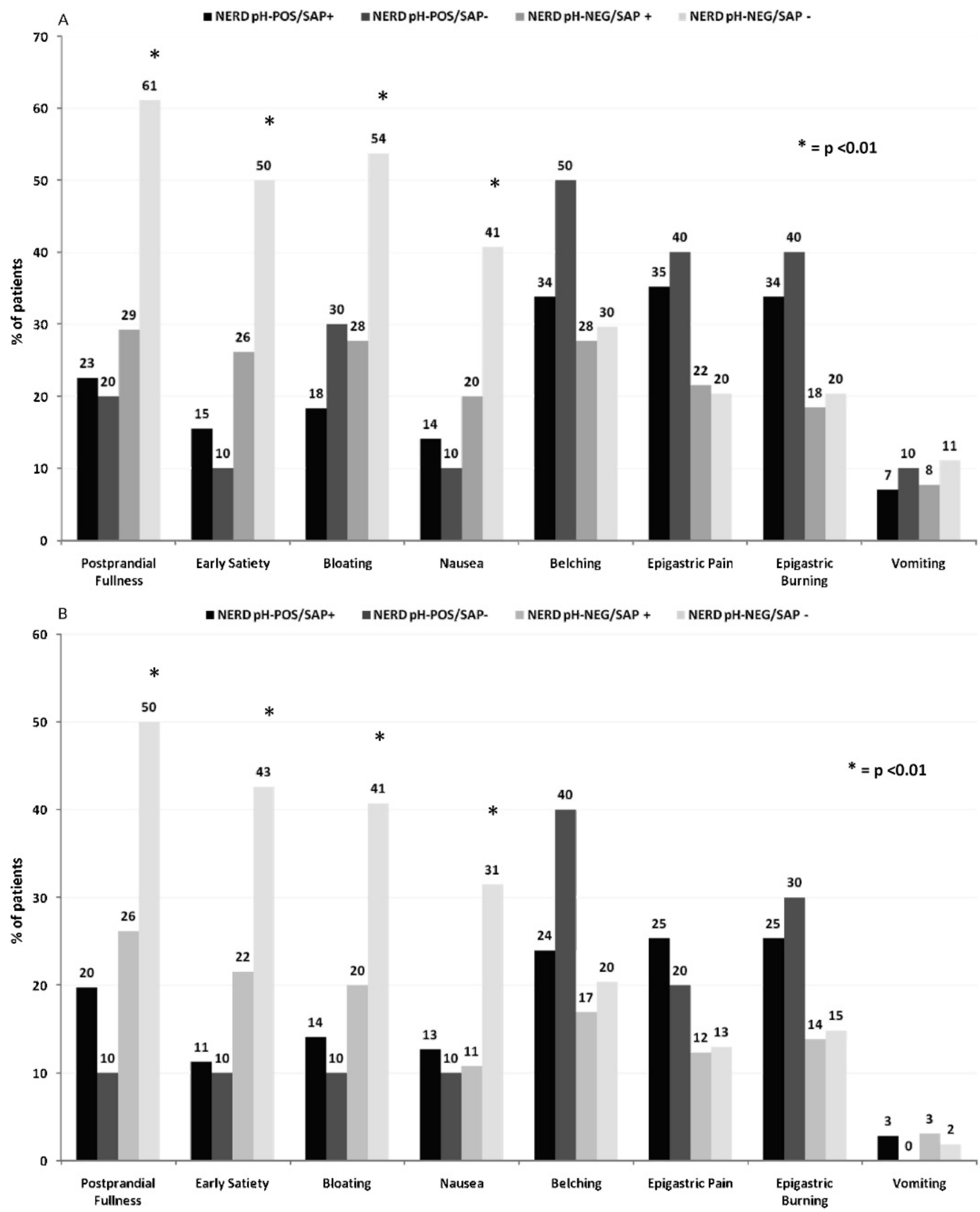

Figure 3 (A) Prevalence of dyspeptic symptoms (score $>0$ ) in patients with non-erosive reflux disease (NERD) subclassified using impedance-pH monitoring $(n=200)$. (B) Prevalence of moderate/severe dyspeptic symptoms (score $\geqslant 2$ ) in patients with NERD subclassified using impedance-pH monitoring $(n=200)$. NEG, negative; POS, positive; SAP, symptom association probability. 
development of GORD and, particularly, abnormal pH monitoring. ${ }^{1025-27}$ These features may help to identify patients with NERD and with an abnormal pH-impedance monitoring. Moreover, we demonstrated a higher prevalence of female gender in the $\mathrm{FH}$ subgroup, as it has been reported in the functional dyspepsia population and generally in patients with functional disorders. ${ }^{178-30}$ No differences based on age, tobacco use, alcohol and coffee consumption, prevalence of $H$ pylori infection could be demonstrated in our population. This is in agreement with various studies ${ }^{20} 27$ showing that these factors are not peculiar of anyone of our subgroups.

One limitation of our study is the lack of outcome prospective data as no information on the response to a standardised therapeutic approach in the described patient groups are currently available. However, considering the previous response to PPI treatment referred to by the majority of our patients before entering the study we can argue that patients with abnormal distal oesophageal acid exposure and/or positive symptom association and dyspeptic symptoms do respond better to antisecretive treatment compared to patients with negative symptom association and dyspeptic symptoms. Evaluating patients on a Mediterranean diet could also be regarded as a shortcoming of the present study with the argument that it was not refluxogenic enough to induce symptoms. While being cognisant of this problem we chose the Mediterranean diet in order to be able to compare the results in patients with NERD with those collected in healthy Italian volunteers and, on the other hand, trying to minimise dietinduced variation in the amount of gastro-oesophageal reflux. Last, but not least, the 30 day washout period before the upper endoscopy in patients using acid suppressive medication could have been too short for lesions to develop. Still, in our experience, this represents the maximum we can ask of patients in order to obtain good compliance and without them dropping out from the study. Moreover, the incidence of recurring erosive lesions after a shorter period of PPI cessation remains unknown.

In conclusion, the present study underscores the important overlap between functional dyspepsia and NERD. This argues for the need to monitor dyspeptic symptoms and both acid and non-acid reflux episodes in patients primarily diagnosed with NERD to help identify the proportion of patients with true FH, who should, preferably, be included in the overall population with functional gastrointestinal disorders and should not be considered as a GORD subgroup any more. We believe this deliberate separation would spare these patients from wasteful and protracted courses of years of acid suppression and, above all, prevent potentially disastrous exposure to surgical options. Prospective outcome data are now needed to show the clinical significance of these findings in respect of future definition of NERD. Of particular interest would be the prospective evaluation of the response to acid suppressive therapy of NERD pH-POS and NERD pH-NEG/SAP+ for acid patients against NERD pH-NEG/SAP+ for non-acid and the response to reflux reducing therapies of NERD $\mathrm{pH}-\mathrm{POS}$ and NERD $\mathrm{pH}$ NEG/SAP+ for acid and non-acid patients against NERD pHNEG/SAP - patients. This possible redefinition as suggested in the present manuscript might impact upon the epidemiology, pathophysiology and natural history of the respective disorders.

\section{Competing interests: None.}

Ethics approval: The study protocol was approved by the local Ethics Committees in November 2003 and was performed according to the Declaration of Helsinki.

\section{REFERENCES}

1. Kahrilas PJ. Gastroesophageal reflux disease. JAMA 1996;276:983-8.

2. Spechler SJ. Epidemiology and natural history of gastroesophageal reflux disease. Digestion 1992;51(Suppl 1):24-9.

3. Smout AJPM. Endoscopy-negative acid reflux disease. Aliment Pharmacol Ther 1997:11(Suppl 2):81-5.

4. Lind T, Havelund T, Carlsson R, et al. Heartburn without esophagitis: efficacy of omeprazole therapy and features determining therapeutic response. Scand J Gastroenterol 1997;32:974-9.

5. Fass R, Fennerty MB, Vakil N. Non-erosive reflux disease (NERD) - current concepts and dilemmas. Am J Gastroenterol 2001:96:303-14.

6. Galmiche JP, Clouse RE, Balint A, et al. Functional esophageal disorders Gastroenterology 2006:130:1459-65.

7. Fass R, Naliboff B, Higa L, et al. Differential effect of long-term esophageal acid exposure on mechano-sensitivity and chemo-sensitivity in humans. Gastroenterology 1998:115:1363-73

8. Savarino $\mathbf{E}$, Zentilin $\mathrm{P}$, Tutuian $\mathrm{R}$, et al. The role of non-acid reflux in NERD - Lessons learned from impedance-pH monitoring in 150 patients off therapy. Am J Gastroenterol 2008:103:2685-93.

9. Justin C, Wu Y, Carrian M, et al. Distinct clinical characteristics between patients with nonerosive reflux disease and those with reflux esophagitis. Clin Gastroenterol Hepatol 2007:5:690-5.

10. Locke GR, Talley NJ, Fett SL, et al. Prevalence and clinical spectrum of gastroesophageal reflux: a population-based study in Olmstead County, Minnesota. Gastroenterology 1997;112:1448-56.

11. Watson RGP, Tham TCK, Johnston BT, et al. Double blind cross-over placebo controlled study of omeprazole in the treatment of patients with reflux symptoms and physiological levels of acid reflux - the 'sensitive oesophagus'. Gut 1997;40:587-90.

12. Zimmerman J, Hershcovici T. Bowel symptoms in non-erosive gastroesophageal reflux disease: nature, prevalence and relation to acid reflux. J Clin Gastroenterol 2008:42:261-5

13. Tack J, Caenepeel P, Fischler B, et al. Hypersensitivity to gastric distention is associated with symptoms in functional dyspepsia. Gastroenterology 2001; 121:526-35.

14. Zentilin $\mathbf{P}$, liritano E, Dulbecco $\mathrm{P}$, et al. Normal values of 24 -h ambulatory intraluminal impedance combined with pH-metry in subjects eating a Mediterranean diet. Dig Liv Dis 2006;38:226-32.

15. Sifrim D, Castell D, Dent J, et al. Gastro-oesophageal reflux monitoring: Review and consensus report on detection and definitions of acid, non-acid, and gas reflux. Gut 2004:53:1024-31.

16. Talley NJ, Zinsmeister AR, Schleck CD, et al. Dyspepsia and dyspepsia subgroups: a population-based study. Gastroenterology 1992;102:1259-68.

17. Quigley EM. Functional dyspepsia (FD) and non-erosive reflux disease (NERD): overlapping or discrete entities? Best Pract Res Clin Gastroenterol 2004;18:695-706.

18. Tack J, Caenepeel P, Arts J, et al. Prevalence of acid reflux in functional dyspepsia and its association with symptom profile. Gut 2005:54:1370-6.

19. Corsetti M, Caenepeel P, Janssens J, et al. Impact of coexisting irritable bowel syndrome on symptoms and pathophysiological mechanisms in functional dyspepsia. Am J Gastroenterol 2004:99:1152-9.

20. Sarnelli G, De Giorgi F, Efficie E, et al. Correlation between oesophageal acid exposure and dyspeptic symptoms in patients with nonerosive reflux disease. Eur J Gastroenterol Hepatol 2008;20:264-8.

21. Tack J, Talley NJ, Camilleri M, et al. Functional gastroduodenal disorders. Gastroenterology 2006;130:1466-79.

22. Talley NJ, Meineche-Schmidt V, Pare P, et al. Efficacy of omeprazole in functiona dyspepsia: double-blind, randomized, placebo-controlled trials (the Bond and Opera studies). Aliment Pharmacol Ther 1998:12:1055-65.

23. Carlsson R, Dent J, Bolling-Sternevald E, et al. The usefulness of a structured questionnaire in the assessment of symptomatic gastroesophageal reflux disease. Scand J Gastroenterol 1998;33:1023-9.

24. Van Oudenhove L, Vandenberghe J, Geeraerts B, et al. Determinants of symptoms in functional dyspepsia: gastric sensorimotor function, psychosocial factors or somatisation? Gut 2008;57:1666-73.

25. Friedenberg FK, Xanthopoulos M, Foster GD, et al. The association between gastroesophageal reflux disease and obesity. Am J Gastroenterol 2008;103:2111-22

26. Pandolfino J. The relationship between obesity and GERD: "big or overblown". Am J Gastroenterol 2008;103:1355-7.

27. Labenz J, Jaspersen J, Kulig M, et al. Risk factors for erosive esophagitis; a multivariate analysis based on the ProGERD study initiative. Am J Gastroenterol 2004;99:1652-6

28. Bolling-Strenevald E, Carlsson R, Aalykke C, et al. Self-administered symptom questionnaires in patients with dyspepsia and their yield in discriminating between endoscopic diagnoses. Dig Dis 2002;20:191-8.

29. Welén K, Faresjö A, Faresjö T. Functional dyspepsia affects women more than men in daily life: a case-control study in primary care. Gend Med 2008;5:62-73.

30. Flier SN, Rose S. Is functional dyspepsia of particular concern in women? A review of gender differences in epidemiology, pathophysiologic mechanisms, clinical presentation, and management. Am J Gastroenterol 2006;101(Suppl 12):S644-53. 